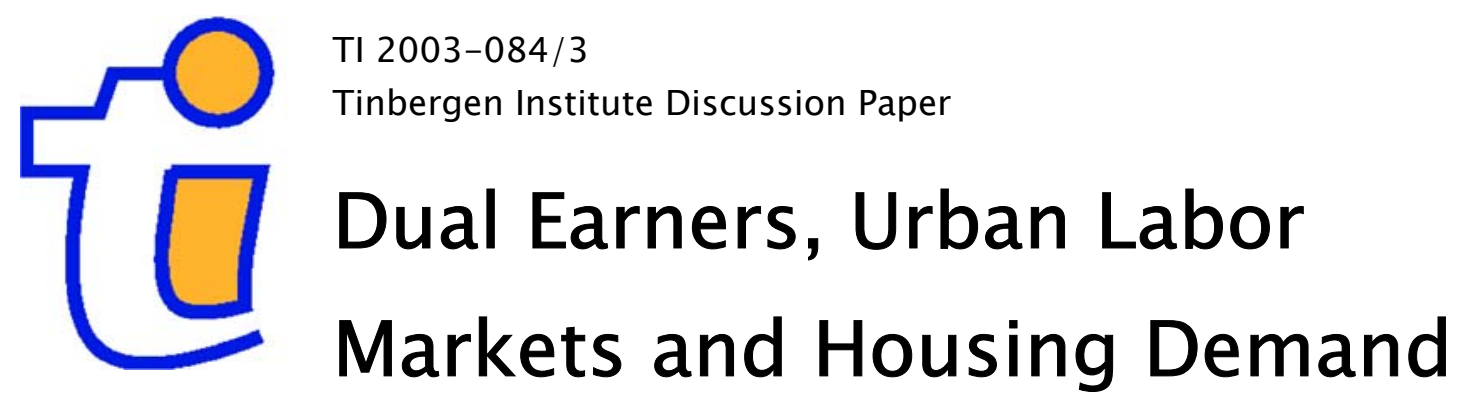

Jan Rouwendall,2,3
Willemijn van der Straaten

' Economics of Consumers and Households Group, Wageningen University, 2Department of Spatial Economics, Faculty of Economics and Business Administration, Vrije Universiteit Amsterdam, 3 Tinbergen Institute. 


\section{Tinbergen Institute}

The Tinbergen Institute is the institute for economic research of the Erasmus Universiteit Rotterdam, Universiteit van Amsterdam, and Vrije Universiteit Amsterdam.

Tinbergen Institute Amsterdam

Roetersstraat 31

1018 WB Amsterdam

The Netherlands

Tel.: $\quad+31(0) 205513500$

Fax: $\quad+31(0) 205513555$

Tinbergen Institute Rotterdam

Burg. Oudlaan 50

3062 PA Rotterdam

The Netherlands

Tel.: $\quad+31(0) 104088900$

Fax: $\quad+31(0) 104089031$

Please send questions and/or remarks of nonscientific nature to driessen@tinbergen.nl.

Most TI discussion papers can be downloaded at http://www.tinbergen.nl. 


\title{
Dual Earners, Urban Labor Markets and Housing Demand
}

\author{
Jan Rouwendal ${ }^{1,2}$ and Willemijn van der Straaten ${ }^{1}$
}

This version: September 29, 2003

JEL Classification: R12, R21, D13

Keywords: dual earner households, power couples, urban wages, location choice, commuting distance, housing demand.

\begin{abstract}
This paper replicates Costa and Kahn's analysis of locational choices of couples of highly educated for the Netherlands. We find increasing concentration of such power couples in the urbanized western part of the country. This trend occurs in spite of the absence of an urban wage premium and the concentration of congestion there. We find that power couples locate more often in medium sized and larger cities than otherwise comparable households and that they are relatively often owner-occupiers and live in more expensive housing. Their commutes are relatively short when it is taken into account that it is more difficult for these households to find suitable arrangements of employment and residence than it is for single earner households. A probable explanation for these findings is that power couples use their relatively large purchasing power to outbid other households from locations that are especially attractive to them, as is predicted by household location theory.
\end{abstract}

${ }^{1}$ Economics of Consumers and Households Group, Wageningen University

${ }^{2}$ Department of Spatial Economics, Free University 



\section{Introduction}

The share of dual earners in the household population has increased considerably over the past decades. Dual earners used to be the exception, but nowadays they are common. Dual earner households are considerably different from single earners in many respects. There are obvious and substantial differences in the way they spend their time. Home production, housework and when children are present - childcare have to be adapted to the working hours of two employed persons. There are also less self-evident ways in which the changing internal organization of households is influencing our societies. One, which is the subject of this paper, is the location behavior of dual earners. Dual earner households may be expected to differ in location behavior from single earners because of the additional home-work interaction and, perhaps, the limited importance of other interactions. This location problem has at least two important aspects. The most obvious one is that it may be more difficult to find a satisfactory employment-housing arrangement when two jobs and one residence are involved, instead of one job and one residence. As a consequence, commutes of dual earners are expected to be longer on average than those of single earners. A second aspect is that dual earners may not only differ in the location they choose within a region, but may also differ in the choices they make with respect to the region of residence. Costa and Kahn (2000) have recently emphasized the colocation problem experienced by 'power couples', that is dual earners that are both highly educated. They argue that satisfactory career perspectives for both partners are only available in the dense local labor markets of metropolitan areas, and show that there is indeed an increasing concentration of 'power couples' in large metropolitan areas in the U.S. in the second half of the 20-th century. In this paper we consider the location behavior of dual earner households in the Netherlands, where the transition towards increased labor market participation of married and cohabiting women took place later than in the US. We find a similar concentration of highly educated dual earners in the Randstad (also called the Dutch Rimcity), the urbanized western part of the country. In contrast to Costa and Kahn, we find no evidence of increasing attractiveness of large urban areas for the control group of highly educated singles, as this group tends to become less concentrated in the Randstad. This leads us to a closer examination of the mechanism that explains the changing location patterns of both groups of households. The colocation hypothesis assumes that labor markets must be sufficiently dense in order to make a region sufficiently attractive for power couples. However, a high density also offers better match opportunities for single earners (including singles). We examine the literature on urban labor market agglomeration in order to find examples of markets that function in such a way that they attract dual earners more than single earners.

An alternative (or additional) explanation for the observed location patterns in the Netherlands considers the effect of dual earners on the housing markets. Dual earners have a household income that is higher than that of single earners. As a consequence, they may be able to outbid the other household types from the most attractive parts of the housing markets in their preferred employment regions. Given the limited supply of newly constructed housing and the small geographical scale of the Netherlands, the other household types may choose lower quality housing in these regions or choose a residence in the neighboring region while accepting longer commutes.

The next section analyses the geographical spread of power couples, adopting the same methodology as Costa and Kahn (2000). Section 3 investigates some labor market issues: the properties that cause the colocation problem and the existence of an urban wage premium in the Netherlands. In section 4 we consider housing market behavior of dual earners and in particular of power couples. Section 5 concludes. 


\section{Location of power couples in the Netherlands}

In this section we examine the question whether the trend that was identified by Costa and Kahn for the United States is also present in the Netherlands. In doing so, we should of course recognize the difference in size between both countries. The US has more than 200 million inhabitants, whereas the Netherlands has less than 20 million. The US has a number of metropolitan regions, whereas the Netherlands has essentially one: the Randstad. This means that we will actually consider the distribution of different household types over a small country consisting of one metropolitan area and its hinterland.

\subsection{Preliminaries}

\section{The data}

The data that we use are those of a series of Housing Needs Surveys. The Housing Needs Survey is conducted every 4 or 5 years and the sequence started in 1973. We use the surveys of 1981, 1989,1993 and 1998 in this paper. Although the Surveys are directed primarily towards the identification of housing needs, they contain a wealth of related relevant information about household characteristics and location.

The analysis of this section refers to respondents and their partners who were in the age interval (23-39) in order to facilitate the comparison with Costa and Kahn (2000). Power couples were identified as couples with both partners highly educated. In order to be qualified as highly educated an individual should have completed higher vocational training or have obtained an university degree.

Having received higher education became increasingly common among both males and females over the period under study, and the share of power couples increased from 7.0 in 1981 to 13.1 in 1998. Female labor force participation also increased considerably. In 1981, 43.7 of the low power couples were dual earners and $63 \%$ of the power couples. In 1998 these shares were $22 \%$ points higher for both groups.

\section{Regional division}

The Randstad has a number of special characteristics. It consists of a number of cities of different size that are separated by more or less rural areas. It is possible to consider the largest of these cities, Amsterdam, Rotterdam, Utrecht and The Hague as separate metropolitan areas. However, this approach has not been chosen because these cities are so close to each other that it is possible to commute from one to another. If we want to define a metropolitan area in such a way that (to a close approximation) all people who live within its boundaries are also employed there, any further decomposition of the Randstad becomes problematic. For this reason the Netherlands is often divided into three areas: the Randstad (dark grey in Figure 1), a Peripheral zone (white in Figure 1) and an area between these two that is referred to as an Intermediate zone (grey in Figure 1). We follow this practice here and consider the question how power couples have located over these three zones during the period 1981-1998.

\section{[Insert Figure 1]}

It must be recognized that this regional division is conceptually different from that employed by Costa and Kahn. They were able to distinguish a large number of metropolitan areas of medium and large size that could be considered as separate labor markets because of spatial separation. 
We divide a small country into the Randstad, a heavily urbanized region, an Intermediate zone, which surrounds the Randstad geographically and the remainder of the country, referred to as the Periphery. Commuting flows between these three regions are not negligible and they can therefore not be considered formally as completely independent regional labor markets. Similar remarks can be made with respect to their functioning as separate marriage markets for power singles.

\section{Trends in the spatial distribution of household types}

Table 1 shows the distribution of three types of households over the three regions discussed above. Power couples are defined as couples where both partners have received higher education. Higher education is defined as higher vocational or university training. In part power couples one of the partners has received higher education, whereas the other has not. Neither partner in low power couples has received higher education. The table shows that power couples became increasingly concentrated in the Randstad and that the share of part power couples living in the Randstad also increased, but at a slower rate as the power couples. The share of low power couples decreased. This suggests that the Randstad became a more attractive residential area for power couples and one may wonder what causes this phenomenon.

[Insert Table 1]

\subsection{Analysis}

\section{The procedure}

As was discussed above, Costa and Kahn (2000) argue that the facilities that dense urban labor offer for both partners is the main explanatory factor. They do so by comparing the changes in the location of power couples with those of other groups. They argue that there are three main factors that determine the trends in the spatial distribution of people: the colocation problem, urban amenities of general interest (for example higher returns for education or cultural activities) and urban amenities of specific interest for singles (for example the existence of a marriage market as a result of an increase of young unmarried singles in large city's). They try to disentangle these three factors by means of two differencing procedures.

In the first procedure, changes in the spatial distribution of so-called 'coincidental couples' are subtracted from changes in the distribution of actual couples (power or low power couples). The distribution of coincidental couples is the distribution of couples that could be expected on the basis of the distribution of singles (power or low power singles). It is determined on the basis of a simple theory of couple formation. The number of potential of matches between males and females that could form within a particular area is the minimum of the number of males and females in a particular region. The distribution of coincidental couples is computed as the distribution of these potential matches. Changes in the distribution of coincidental couples are driven by changes in urban amenities of general interest and changes in urban amenities of specific interest for singles. Changes in the actual distribution of couples are driven by colocation problems and urban amenities of general interest. An overview of the urban amenities for various types of couples is given in Table 2 .

[Insert Table 2] 
The effect of urban amenities of general interest can be removed by taking the difference between the changes in the spatial distribution of actual couples and coincidental couples. They compute this difference both for power couples and for low power couples.

The resulting double differences are determined by the colocation problem and by the urban amenities that are of specific interest for singles. In the second procedure, the difference of these double differences is computed. If it is assumed that the effects of urban amenities that are of specific interest to singles are equal for both power and low power singles, this leaves us with the effect of the colocation problem that is specific for power couples. Costa and Kahn conclude on the basis of the resulting triple difference that a substantial part of the total changes in the location pattern of power couples is caused by the colocation problem.

Results

We used the procedure developed by Costa and Kahn for our Dutch data. The results are reported in Table 3. The first three lines in this table summarize the changes in the location patterns of four couple types over the period concerned. The Randstad attracted a large share of power couples, but became less attractive for the other three types. The next two lines show the double differences.

[Insert Table 3]

The bottom line of the table shows the computed effect of the specific colocation problem for power couples. One surprising aspect of these figures is that they suggest that locating in the Intermediate zone is better for solving the colocation problem than locating in the Randstad. Another is that they are larger (in absolute value) than the changes reported in the first row of the table. This indicates that the increasing concentration of power couples in the Randstad and the Intermediate zone took place despite a decreasing attractiveness of this region in terms of amenities of general interest.

Costa and Kahn also carried out the procedure for power couples that are dual earners only, as a refinement of their initial analysis. We did the same and found somewhat different results. The lower panel of Table 3 shows that the colocation effect for the Randstad is now 0.142 , that for the Intermediate zone -0.15 and for the Periphery -0.118 . These results suggest that the Randstad offers the best possibilities to solve the colocation problem.

\section{Discussion}

It should be clear that the procedure adopted by Costa and Kahn is based on strong assumptions with respect to the effect of the three factors that are distinguished upon the location patterns of the groups concerned. Changes in the share of a group of households in a particular region must be the sum of two effects. Moreover the coefficients referring to urban amenities in general must either be equal for the pairs (power couple, coincidental power couple) and (low power couple, coincidental low power couple) or for the pairs (power couple, low power couple) and (coincidental power couple, coincidental low power couple). Costa and Kahn assume the first possibility to be the relevant one. If one adopts the second possibility, the effect of the colocation problem can be found by subtracting the changes in the regional distribution of low power couples from those of high power couples and there would be no need to take triple differences. Finally, the coefficients referring to urban amenities of specific interest to singles should be equal for power and low power singles. These assumptions are not motivated by, for instance, a model of location choice of households. They should probably be interpreted as approximations to such 
a model, but it is far from clear that, for instance, a first order approximation to such a model has the properties assumed by Costa and Kahn.

On the other hand, it is also clear that the differencing procedures used have attractive properties in that they correct potentially for effects of all types of omitted variables, even though it must be noticed that also here the assumption of linearity is crucial.

One potentially important criticism of the procedure used is that it is doubtful whether the Randstad and the Intermediate zone can be considered as separate labor and/or marriage markets.

\subsection{Conclusion}

The increasing concentration of power couples in the most urbanized part of the Netherlands is in line with the trend that has been observed by Costa and Kahn for the US. A replication of their analysis for Dutch data suggests that the colocation problem is an important determinant. In contrast to the United States, however, it seems to be the case that the effect of the colocation problem is counteracted by changes in the attractiveness of the Randstad in terms of urban amenities of general interest and amenities that are of special interest for singles. In other words: power couples would have become even more concentrated in the Randstad if urban amenities had remained as attractive as they were in the beginning of the eighties. This leads to two further questions.

First, what exactly is the colocation problem? The analysis that has been carried out in the present section results in the conclusion that the colocation problem is of considerable importance for the spread of power couples over the Netherlands. However, it reaches this conclusion on the basis of a differencing procedure that intends to remove all other explanations. It does not provide direct insight into the colocation problem itself. For that purpose we must turn to labor market analysis. A second question that emerges from the analysis is: why has the Randstad become less attractive apart from the possibilities it offers for solving the colocation problem? Again, the data considered thus far cannot tell us the answer. Costa and Kahn relate the increased attractiveness of metropolitan areas in the US to changes in the urban wage premium. This suggests again that we should turn to labor market analysis for an explanation for what happens in the Netherlands. We do so in the next section.

\section{Urban Labor Markets}

Local labor markets play an important role in Costa and Kahn's analysis: first, they argue that only metropolitan labor markets are dense enough to offer both highly educated partners in power couples a reasonable career perspective and second, they argue that an additional benefit is associated with an urban wage premium that appears to have increased over time. In this section we take a closer look at the urban labor market. In the first place we look at the characteristics that such a market must have in order to facilitate solving the colocation problem. Second, we look at the existence of an urban wage premium for the higher educated in the Netherlands.

\subsection{A closer look at the colocation problem}

\section{What exactly is the colocation problem}

Before we start the review of labor market models that are relevant for the colocation problem, it is useful to take a closer look at the problem itself. Costa and Kahn (2000, p. 1288) introduce it as follows: 


\section{difficulty of finding two jobs commensurate with the skills of each spouse within a reasonable commute from home.}

This seemingly clear statement suggests that a dense labor market, with more jobs available within a reasonable commute from home, makes it easier to solve this difficulty. However, in a dense labor market there are not only more jobs, but also more workers. As a result, there will be more competition for jobs commensurate with the skills of each worker and in a labor market with imperfect information and other market imperfections, its effect may be similar to that of a lower density of jobs.

It should also be noticed that the colocation problem is defined as a problem that is specific to couples. In a given local labor market it may be difficult for both workers to find a job that is commensurate with their skills. However, if the difference between large and small labor markets is only in the number of jobs and not in the distribution of the skills required for carrying out these jobs, there seems no reason to talk about a specific colocation problem.

It is, of course, true that dual earners have to find a combination of two employment locations and one residential location with reasonable commutes, whereas single earners have a simpler problem to solve. However, this refers to location within an urban area (we discuss this aspect in the next section) and does not in itself make clear that denser labor markets are more attractive than others.

We may conclude that the colocation problem appears to be a bit more difficult to understand than one might think at first sight. For this reason it seems to be useful to take a closer look at labor market models that deal with the heterogeneity of workers in order to see how the colocation problem may emerge in such a context.

\section{The extent of the market, search and learning}

Frank (1978) may have been the first to attempt a formal analysis of the colocation problem in his study of the effects of affirmative action. In his model jobs and workers are heterogeneous. The productivity of a particular match between a worker and a job is highest if the required skill level equals the offered skill level. If the two skill levels are unequal, productivity diminishes proportional to the absolute value of the difference. A single worker will locate in a large city if his personal match is better there than elsewhere. Dual earners will locate in the large city if the sum of the individual discrepancies is smaller in the large city than elsewhere. Frank discusses a particular simplified situation and shows that the probability that the latter event takes place is larger than the probability that the first event takes place. This suggests that dual earners will more often choose the large labor market than single earners.

Frank's analysis leads to a clear conclusion, but it is clearly partial in nature. This evokes the question whether his conclusion continues to hold in a more general setting where less is assumed to be constant. Fortunately, there have been other analyses of the functioning of the type of labor market with heterogeneous labor that he studied, which are less restrictive. Kim (1989), referred to by Costa and Kahn, provided a model in which labor is heterogeneous in innate abilities of the workers. This setting is similar to that considered by Frank, but Kim also considers the effects of bargaining. One of his results is that in a sufficiently competitive market the wage is independent of the discrepancy between a worker's actual ability and the one that is optimal for the job in which he is employed. In such a market the mechanism identified by Frank clearly doesn't work. Kim also shows that in a larger market the wage level will be higher than in a smaller one. He does not discuss the peculiarities of dual earner households, but the relevant consequences of his model are not too difficult to grasp. In his model both wage earners can earn more in the large 
market than in the small one, independent of the discrepancy between their ability and the ideal one for the job in which they are employed. For both workers the advantage of the higher wage is equal and for each of them the benefit of locating in a large city is identical to that of a single worker. In this sense there is no real colocation problem in this model. However, note that this reasoning assumes that wage differences between large and small markets remain in existence, whereas it must be expected that in general equilibrium context they will be removed. When placed in a spatial setting, the analysis of Kim can be interpreted as an agglomeration effect. Helsley and Strange (1990) have indeed developed a model for a system of cities in which the better matching of skills and requirements is the reason why cities exist. A counteracting force is the consumption of land, which forces workers to commute over longer distances when city size increases. Workers move between cities in order to maximize expected utility. The equilibrium size of the city is determined by the agglomeration and disagglomeration effects. Although Helsley and Strange only consider cities are of equal size, it is possible to imagine that this model contains cities of different sizes, for instance, because of exogenous differences in the attractiveness of sites or the productivity of workers. In a general equilibrium setting all workers will experience the same utility, independent of their place of residence. There is no specific colocation problem.

Teulings and Gautier (2000) consider a model in which skills and job requirements are continuously distributed on the real line. Under conditions of perfect information a Walrasian equilibrium exists in which each job type is matched to exactly one worker type. Imperfect information introduces 'noise' around the Walrasian equilibrium. In Teulings and Gautier (2002) they apply the model in a spatial general equilibrium setting. In equilibrium, all workers are indifferent between regions. The less dense regions are more specialized than the denser regions. In this setting a colocation problem may emerge. In the spatial general equilibrium, dense regions specialize in products that require a diversity of skills, whereas less dense regions specialize in products requiring specific skills. This means that the distribution of required skills depends on the density of economic activity in a region and has the largest variance in the densest regions. If skills of individual workers are a random drawing from a given skill distribution (independent of their regions of origin) and if they match randomly into couples, it is obvious that some redistribution of the workers over the regions has to take place in order to establish this equilibrium. Workers with skills located at the tails of the distribution must move from rural to urban areas, or workers with skills located close to the median must move in the reverse direction (or both). Since there are relatively few workers with skills located at the tail of the distribution, the probability that they have a partner with skill located close to the median is relatively large. These partners may face conflicting interests with respect to their preferred location, and it is conceivable (even though we do not undertake a formal analysis) that the best way to solve this problem is to move to a dense urban region where job opportunities for both of them are available.

Teulings and Gautier stress that their results depend on their assumption that there are increasing returns to scale in the matching function. The survey of Petrongolo and Pissarides (2001), to which they refer, makes clear that empirical support for this assumption is weak. However, Teulings and Gautier argue that it may be difficult to observe these increasing returns when present, because of counteracting effects, such as an increase in reservation wages. A more recent paper of Petrongolo and Pissarides (2002) offers some support for this point of view, but also observes that it implies that the effect of increasing returns should show up in the wage rates paid in the denser labor markets. In the next subsection we will examine the existence of an urban wage premium for the Randstad area. 
In conclusion it may be said that it is not easy to motivate the existence, let alone the significance, of the colocation problem on the basis of existing labor market models. We focused attention on models that explicitly incorporate the heterogeneity of labor, since this seems to be a main ingredient of the problem. A necessary condition for the colocation problem to emerge seems to be that the distribution of required skills differs over regions and has the largest variance in dense urban labor markets. This condition does not appear to be unrealistic. However, it is not obvious from Costa and Kahn's statement of the problem, and it is (no doubt for reasons of simplicity) not incorporated in most existing models.

\section{Other labor market effects}

The models discussed above stress the problems associated with matching heterogeneous workers to equally heterogeneous jobs and the advantages that large (urban) labor markets offer in this respect. However, this is not the only conceivable benefit of urban labor markets. Glaeser and Maré (2001) have studied the urban wage premium and find that on average it takes some time to realize. If the main benefit of urban labor markets is a better match between required and actual capacities, it should be expected that this premium is realized immediately, or at least soon after arrival on the urban labor market. Since the data show that it usually takes some years for workers to realize this premium, it may be conjectured that something is missing from these matching models that is relevant in practice.

Glaeser (1999) argues that learning of workers from each other is the explanation. Experienced workers meet inexperienced colleagues and the exchange of ideas makes the latter more productive. The relevant contacts may occur on the job, but also outside working hours in informal contacts that are facilitated by the high density of the urban environment. Power couples may be in an especially advantageous position to realize such benefits. Research indicates that the diversity of activities is especially important for the agglomeration effects and economic growth to realize. Iranzo (2003) presents evidence that wages are higher in cities with more dispersed human capital.

Peri (2002) developed a model in which learning externalities among educated workers are the reason for their concentration in urban areas. He argues that the development of ICT in the last quarter of the twentieth century has increased the importance of such externalities and provides an alternative explanation for the increased concentration of power couples in urban areas, while it also explains a similar trend among highly educated singles in the US. However, Dutch data do not show a similar trend.

\section{Conclusion}

In the previous section we found, using the methodology developed by Costa and Kahn (2000) that the concentration of power couples in the western part of the Netherlands increased despite the decreasing attractiveness of this region in other respect. This suggests that the colocation problem is an important driving force of the spatial development. It is therefore important to understand it, and for that reason we turned to labor market models. However, we found it somewhat difficult to find a place for the colocation problem in these models. The main problem seems to be that most of them assume an identical distribution of required skills in all regions. This is different in Teulings and Gautier (2002) who develop a model in which the distribution of required skills is more dispersed in dense regions. This implies that such regions have an advantage for couples in general. They stress the dependence of their results on the assumed increasing returns in the matching function and admit that there is not much evidence supporting this property of their model. Other labor market models that focus on urban regions, concentrate 
on the urban wage premium and seem to offer little additional insight into the colocation problem. It seems therefore fair to conclude that more detailed research in the location behavior of dual earner households and especially power couples is needed in order to gain a better understanding of the colocation problem. Since this is clearly outside the scope of the present paper, we now turn to the second subject of this section, regional differences in wages.

\subsection{Regional wage differences in the Netherlands}

\section{Introduction}

In the remainder of this section and in the next one, we take a closer look at a number of labor and housing markets aspects that are relevant for understanding the location behavior of dual earners and, more specifically, power couples. We do this by means of an in-depth analysis of the data from the Housing Needs Survey of 1993. Concentrating on a single cross section offers us the opportunity to investigate a number of relevant topics in greater detail than would have been possible by examining a number of cross sections.

Before starting to discuss this issue, we should mention that the analyses that follow are not restricted to people aged 23-39, but concern in principle all respondents.

\section{Is there an urban wage premium in the Netherlands?}

What do Dutch data tell us about the spatial aspect of the relation between education, household composition and wages? The Housing Needs Survey of 1993 provides relevant information. We computed hourly wage rates for workers and regressed these on age, gender and education variables. The Housing Needs Survey does not indicate work experience, and the effects of this variable should therefore be expected to influence the estimates of other variables. When dealing with regional differences we have included dummies for the Randstad and the Intermediate zone, treating the Periphery as the reference region. Results are presented in Table 4.

\section{[Insert Table 4]}

The basic regression (1) relates natural logarithm of the hourly wage rate to age, gender and education. It does not yet include household characteristics or spatial variables. The natural logarithm of the wage rate increases with age, but at a decreasing rate. Female workers have a wage rate that is on average $28 \%$ lower than that of males. Those with only basic education earn $10 \%$ less, those with higher vocational or university training $20-30 \%$ more than the reference group with intermediate education. The positive effects of higher vocational or university training are somewhat higher for females than for males, although the difference is not large enough to close the gender wage gap for the higher educated.

The next regression introduces household characteristics. Singles have lower wage rates than workers belonging to single earner households. If the single person is female, most of this effect disappears. Dual earners have on average a wage rate that is $4.7 \%$ lower than that of otherwise comparable single earners. Note that we have controlled for gender effects by including the product of the dummies for females and dual earners as a separate variable. The negative coefficient may indicate that both earners give up some of their career perspectives in order to solve the difficulties involved in finding a suitable arrangement of the other relevant aspects. The lower wage rate may therefore be an aspect of the colocation problem. Female earners in dual earner households are not significantly different from males in this respect. The indicator for 
power couples does not have a significant coefficient, but the female workers belonging to such a household have on average a higher wage rate than their otherwise comparable colleagues.

As a result of the introduction of household characteristics, the gender specific effects of higher education become insignificant. Female workers belonging to power couples earn $7 \%$ more than their otherwise comparable colleagues. ${ }^{1}$ If we leave out the cross effect of gender and power couple, the cross effect of gender and university education becomes significant again. In regression (3) we introduce dummies for workers located in the Randstad and in the Intermediate zone. Estimation results show that otherwise equal workers who live in the Randstad earn on average a wage rate that is $6 \%$ higher than those living in the Periphery, whereas workers who live in the Intermediate zone earn $1.6 \%$ more. It is tempting to interpret these results as a confirmation of the existence of an urban wage premium caused by agglomeration effects of better matching or learning. However, the cross-effects of living in the Randstad or the Intermediate zone and having a university education are negative, and make clear that these highly educated workers do on average not earn a higher wage outside the peripheral areas, and may indeed earn a somewhat lower wage rate in the Intermediate zone. This surprising result does not show up for workers with a higher vocational training.

If the advantages of a large labor market that were highlighted in the models discussed above do indeed exist, one would expect that they are especially relevant for the university trained, who are often highly specialized. If the higher wage that is in general paid in the Randstad compensates for the disadvantages of working in an urban environment, such as congestion, traffic noise, high house prices, et cetera, one expects that university trained workers have to be compensated as much as others. Whatever may be the explanation, the results cast doubt on the hypothesis that the urbanized part of the Netherlands is an attractive place to live for university trained people.

\section{Is there direct evidence of a colocation problem in the data?}

If Frank (1978) and Costa and Kahn (2000) are right and there exists an important colocation problem, one would expect that dual earners in the peripheral parts of the country on average earn less than elsewhere. Even in a general equilibrium setting this effect should show up if a sufficiently large number of such couples preferred to stay in peripheral areas because of family ties that compensate for a somewhat lower wage, et cetera. In order to see whether such effects can be detected, we introduced a number of additional cross-effects into our estimating equation. Estimation results of equation (4) show that dual earners or power couples do not earn significantly more in the Randstad or in the Intermediate zone than elsewhere in the country. Also, the wage rates of female workers in such households in the Randstad or the Intermediate zone are not different from those living elsewhere. This shows that in the Netherlands workers belonging to power couples did not earn significantly more in the Randstad or intermediate part of the country than in the Periphery. Earlier regressions showed that female workers belonging to power couples have higher wage rates than their otherwise comparable colleagues, but this effect is no longer significant in (4).

\section{Conclusion}

The results of the empirical analysis are at first sight somewhat puzzling. We could not identify an urban wage premium for university educated workers, but workers with higher vocational training appear to earn somewhat higher wages in the Randstad and the Intermediate zone.

\footnotetext{
${ }^{1}$ See Bernasco (1994) for an analysis of the effects of resources of one partner on the career of the other.
} 
However, this finding does not contradict the possibility that the denser labor market in these regions offers power couples possibilities to solve their colocation problem. Moreover, the absence of an urban wage premium for the Randstad, combined with the disadvantages of urban life such as congestion, noise, lack of recreational facilities, et cetera may well explain why the attractiveness of the Randstad in terms of urban amenities of general interest would in itself induce power couples to concentrate less in this region, as was found in the previous section. The lack of direct evidence of a colocation problem in the form of lower wages for these workers in the Periphery may be caused by the fact that many power couples avoid the realization of such a situation by locating in the Randstad and Intermediate zone. Moreover, power couples that succeed in finding relatively bright career perspective for both partners will probably stay in the Periphery, thereby introducing a selection effect that works in the opposite direction.

Our ultimate conclusion is therefore that the results of the empirical work reported in the second part of this section are consistent with those of the analysis carried out in section 2 . The effects of the colocation problem counteract those of other developments that would in themselves have induced power couples to locate outside the Randstad and the Intermediate zone, especially when they are educated at a university.

\section{Dual Earners and the Housing Market}

\subsection{General Considerations}

In this section we look at the location choice of power couples at a more detailed level by considering their housing consumption and location within urban areas.

The monocentric model provides a convenient starting point for studying the locational behavior of households. We consider a basic version of the model in which all employment is located in the city center (CBD) and all jobs are identical. Some workers belong to single earner households, others to dual earner households. The latter households have twice the income of single earner households, and two workers, instead of one, have to travel to the CBD each day. Unless the demand for residential land has a very high income elasticity, the model predicts that dual earners have steeper bid rent functions and will therefore concentrate around the city center, leaving the suburban areas for the single earners. We will not elaborate this reasoning by means of a formal model. However, it would not be difficult, for instance, to introduce dual earners in this way into the model of Helsley and Strange (1990) discussed in the previous section and show that in each city dual earners will locate close to the CBD, whereas single earners have larger home-work distances. ${ }^{2}$

In practice, things are not as simple as is suggested by the highly stylized monocentric model. A significant problem is that the predictions of the monocentric model with respect to the inner-city locations of various income groups are difficult to reconcile with empirical evidence about the location of high income groups in urban areas in American cities. This was first shown by Wheaton (1977) and recently confirmed by Glaeser, Kahn and Rappoport (2000). Possible explanations for this anomaly are the durability of housing (older housing is concentrated in inner cities), and in the provision of special housing and (public) transport facilities in inner cities. Although European cities are considerably different from American ones in a number of respects, the basic economic forces seem to be the same. In the Netherlands the largest cities have long concentrated their housing policies on providing affordable housing for low income groups, and this has resulted in a relatively large rental sector. At the same time, (national) tax facilities for

\footnotetext{
${ }^{2}$ See Freedman and Kern (1997) for a more extensive analysis and empirical work.
} 
owner-occupiers (including unlimited deductibility of mortgage rent from taxable income) are especially in favor of higher income groups. It is therefore unsurprising that there is a close relationship between income and the probability that a household is owner-occupier. Moreover, the share of the rental sector in the dwelling stock is highest in the largest cities and, more generally, is increasing in city size. High-income households, and most power couples will belong to this group, tend to be owner-occupiers and live outside the largest cities.

It is therefore possible that the empirical relationship between income and residential location within urban areas in the Netherlands is the opposite of what is predicted by the monocentric model, as is the case for the American cities. High income households have to choose between two unattractive combinations: short commutes combined with old inner city housing and long commutes combined with modern housing.

Although Americans seem to have opted en masse for the latter possibility, it must not be forgotten that there is more than one difference between the monocentric model and reality. A second important discrepancy results from the fact that the monocentric model assumes that all employment is concentrated in the city center, whereas in reality jobs are much more evenly spread over space. This results in better possibilities for combining a residential location outside the core urban area with a commute of limited length. The monocentric model is often thought of as fitting the American cities of some decades ago better than it ever fitted European cities. When the Randstad is regarded as a single urban area, it clearly has many employment centers and the large cities in this area (such as Amsterdam and Rotterdam) have more than one employment center of their own. This means that it may have been possible for high income households to realize the best of both worlds by realizing a combination of modern owner occupied housing and limited home-work distances. In the remainder of this section we will investigate this issue in some detail.

On the other hand, it must also be recognized that dispersed unemployment increases the problems that dual earner households have in finding a satisfactory combination of employment and residential location. If the jobs of both workers are located at the same site, there is effectively only one job location, and the residential location problem is essentially the same as that of a single-worker households. When the locations of the two jobs are different, as is usually the case in practice, the problem becomes more difficult to solve with limited commutes for both workers and this aspect of the colocation problem may well result in longer average commutes for both workers. This may especially be the case for workers belonging to power couples, who both face a thin labor market.

In what follows we have as a rule used the workers of single earner households as our reference group and included dummies for dual earners, singles and power couples and power singles. With respect to education we introduce dummies for higher vocational and university training and for basic education only, treating the group of workers with intermediate education as our reference group.

\subsection{Commuting distances}

We start with an examination of the commuting distance. On the basis of search theory it may be argued that this is a random variable and that the parameters of its distribution are dependent upon the spatial characteristics of relevant housing and employment opportunities in the area concerned. ${ }^{3}$ These opportunities are in large part related to the worker's education, age and gender. Column (1) of Table 5 shows estimation results for a simple regression equation in which

\footnotetext{
${ }^{3}$ See, for instance, Rouwendal and Rietveld (1994).
} 
the natural logarithm of the commute, measured in kilometers is related to these basic worker characteristics. Males have longer commutes than females, older workers than younger workers, higher educated than low educated. Explanations for these well known phenomena are that household responsibilities concentrated around the beginning and the end of the working day are often more pressing for females than for males, that older people are less mobile on the labor market and therefore can easier adjust their residential location to their current job and that the relevant segments of the labor and housing markets for the higher educated are less thick than those relevant for other groups of workers. We added the hourly wage rate and the ratio between the actual number of working hours and those related to a fulltime job and found that part time workers and low paid workers have relatively short commutes.

\section{[Insert Table 5]}

In equation (2) a number of household characteristics were added. Estimation results show that workers belonging to dual earner households do not on average have significantly longer commutes than other workers. Belonging to a power couple only makes a difference for females: they realize longer commutes. Workers have shorter commutes if they have children aged 12-17, and there is an additional effect of children between 6 and 11 on the commute of their mother. ${ }^{4}$ For the purposes of the present paper, the most important aspect of equation (2) is that it provides only weak evidence of longer commutes for dual earners and, more specifically, power couples. These workers seem to be able to solve their colocation problem in a satisfactory way with commutes that are on average close to those of other workers. Before turning to the question how they are able to realize this outcome, we first incorporate the spatial dimension into the analysis. Equation (3) indicates that the commutes of workers residing in the Randstad are in general longer than those in the Intermediate zone, which are in turn longer than those in the peripheral parts of the Netherlands. The longer commutes of university trained workers are restricted to the Randstad and the Intermediate zone. The gender-specific effect of belonging to a power couple is now larger and does not appear to be spatially differentiated.

In order to investigate the effect of living in a particular urban or rural municipality on the commute, equation (4) adds a number of dummies for the size (measured as the number of inhabitants) of the municipality of residence. The shortest commutes are realized in the largest municipalities, and living in a rural area is clearly expensive in terms of commuting times. However, controlling for these effects does not change the estimates for the effects of dual earners or power couples substantially.

\subsection{Location choice}

If workers belonging to dual earner households don't realize longer commutes even though they have to solve a more difficult location problem, they will probably have used means that were not available to others in order to reach this goal. One possibility is that they have different preferences with respect to location, another is that they use their higher income so as to outbid others from the locations that are especially attractive to them. Although the last regression discussed in the previous subsection shows that the former explanation cannot provide a complete explanation, it is nevertheless interesting to consider location choices of dual earners in some detail. In the next subsection we discuss the other explanation.

\footnotetext{
${ }^{4}$ It is, of course, probable that there will also be effects on labor force participation and number of hours worked.
} 
Table 6 shows the results of a simple logit model for the distribution of households over the Randstad, the Intermediate zone and the Periphery. Households with a higher income are more likely to be found in the Randstad and Intermediate zone. However, Dual Earners are in general underrepresented in the Intermediate zone. Power couples show a different pattern: they are more often located in the Randstad. This is, of course, in line with the results of section 2. One other variable in the model is 'power single' which indicates a single person household with higher vocational training or university education. These are more often living in the Intermediate zone and the Randstad than other household types, after controlling for the other variables. Table 7 reports results of a multinomial logit model referring to the choice of the size of the municipality. It shows that households with an older head and a higher income are less likely to be found in big cities. However, dual earners deviate from this trend and are over-represented in medium sized and large cities. Power couples are even more likely to be found in larger cities. Singles are also concentrated (at least in a relative sense) in the big cities, and this is even more true for power singles. This is consistent with Peri's argument that higher educated workers in general tend to concentrate in cities because of externalities associated with learning.

\section{[Insert Table 7]}

The results just discussed by and large confirm the analysis of section 2, which showed that power couples tend to concentrate in metropolitan areas. On a national scale they are more likely to be found in the Intermediate zone and the Randstad. Moreover they tend to live often in medium and large cities and in this respect their location pattern resembles that of singles. However, as we have seen above, they do not realize the shorter commutes of singles, and the female workers in power couples realize longer commutes. This suggests that the dual earners are able to realize commutes that are on average approximately of the same length as those of single earners because their location pattern is different from that group. It is closer to that of singles. This location pattern facilitates shorter commutes than those realized by dual earners in general, but the dual earners actually do not realize these shorter commutes. The probable explanation is, of course, that the colocation problem prevents them from doing this.

\subsection{Housing demand}

We now turn to the second potential explanation mentioned above, according to which the workers belonging to dual earner households realize their relatively short commutes because of their higher income. This means: they outbid others in the locations that are especially attractive to them. This is only possible in the owner-occupied segment of the market, since rents are still by and large regulated in the Netherlands. ${ }^{5}$ We would therefore expect that dual earners and power couples are over-represented in the owner-occupied part of the market and reside in relatively expensive housing.

\section{[Insert Table 8]}

\footnotetext{
${ }^{5}$ Rent control in the Netherlands was in the early 1990s somewhat less restrictive than it used to be, but the market still used queuing as an important allocation mechanism. Only in a small part of the market (mostly containing expensive urban housing) there is a free market where prices adjust to equilibrate supply and demand.
} 
Table 8 shows estimation results of a logit model for tenure choice. Households with a higher income are more likely to own. Older and younger heads of households are less likely to be owner-occupiers. A set of spatial dummy variables is included in the model in an attempt to control for the peculiarities of the local housing market. They show that owner-occupation is less common in the Intermediate zone and in larger municipalities. The results do not completely confirm the conjecture that dual earners are more likely to own. When controlling for income and age of the head of the household, dual earners are actually less likely to own house than otherwise comparable single earners. Power couples are different, and the positive coefficient estimated for this group of households more than compensates for the negative coefficient for dual earners.

The negative coefficient for dual earners may be related to the fact that the income of the female worker was until recently not regarded as part of the household's permanent income. Until the nineteen-eighties many women in the Netherlands stopped working or switched to a part-time job when children were born. Also, the maximum possible mortgage level was determined on the basis of the ratio between annual mortgage payments and income of the main breadwinner. The income of the female worker was not included in this computation, implying that dual earner households could borrow less than a single earner household with a comparable income. This practice was abandoned in the beginning of the nineties, and our estimation results can be interpreted as suggesting that power couples were the first to use their increased borrowing capacity.

Next we turn to the value of the owner-occupied house. Dual earner households have two incomes and per capita income in such households will therefore be higher than in otherwise comparable single earner households. Since housing is a normal good, this suggests that the demand for housing services of dual earners will be higher than that of other household types. The effect on housing demand may not be restricted to that of a higher income. We have already seen that dual earners are more often located in medium sized and large cities than single earners. House prices are typically higher in these areas, and this may have an additional positive impact on the value of houses occupied by dual earners. It has also been suggested above that the relatively short commutes of dual earners are facilitated by their location choices. Urban economic models suggest that the mechanism underlying this process will be that dual earners outbid other potential buyers of their most preferred houses. If this happens, it may have an additional positive impact on the volume of housing services consumed.

[Insert Table 9]

Regression (1), reported in Table 9, shows that the value of owner-occupied housing is positively related to income and the age of the head of the household. Dual earners have, all else equal, somewhat less expensive housing, possibly for the same reasons that make them less likely to be homeowners. Power couples differ here also and have more expensive housing. Singles have cheaper housing, although this effect is smaller if they are higher educated. Regression (2) refers to the same equation, but now with the Heckman correction for selectivity added. Incorporation of this additional variable has a substantial impact on most of the included variables, but even though the power couple effect decreases in size, it remains large and highly significant. For our purposes, the main result is this large and positive coefficient for power couples, which outweighs the negative coefficient estimated for dual earners. The estimation results therefore provide evidence that power couples are paying even more for their owner occupied house than could be expected on the basis of their high incomes. This suggests that these households indeed 
outbid others from their most preferred houses, and that the implied commutes play an important role in their willingness to pay for a particular house.

\section{Conclusions}

This paper focused attention on location choices of dual earners and of so-called power couples in particular. It appears from the analysis that the colocation problem is important for these households, both in choosing a particular region as their residence and in choosing a specific location within that region. Our replication of Costa and Kahn's analysis for the Netherlands indicates that power couples prefer the Randstad even though this area became less attractive for other reasons. Further analysis revealed that one of these other reasons is that wage rates for university trained people are not higher in the Randstad or the Intermediate zone than in the Periphery, even though housing is considerably more expensive in the western part of the Netherlands, congestion problems are concentrated there, et cetera.

Within their region of residence, power couples are more often located in the medium sized and large cities, which contributes to their on average relatively short commutes. However, even if we control for region and the size of the municipality, commuting distances of workers belonging to dual earner households and power couples are on average not different from other workers. There is one exception: females in power couples have a longer commute.

It seems therefore that dual earner households, and more specifically, power couples, are able to solve, or at least to mitigate, this aspect of their colocation problem by paying considerable attention to the choice of their residential location relative to the job locations of the two workers. For power couples, this conjecture was confirmed by our finding that they are more likely to be owner-occupiers and if they are, live in more expensive housing than could be expected on the basis of their other characteristics.

In summary, it may be said that we have found a consistent picture of the locational behavior of power couples:

- they locate more often in the densely populated urbanized western part of the country than could be expected on the basis of their other characteristics;

- they do so, even though there is no urban wage premium for university educated people in this part of the country;

- they locate more often in medium and large sized cities than otherwise comparable households;

- they manage to realize housing-employment arrangements that imply commutes that are somewhat larger for the female workers, but not for the males;

- they are more often owner-occupiers than other dual earner households and seem to outbid others from the segments of the housing market they prefer most.

These findings suggest that the increasing importance of dual earner households and, more specifically, power couples has important consequences for the distribution of households over space, both at the national and at the regional scale in the Netherlands. At the national scale the importance of dense labor markets for solving the colocation problem provides an important counteracting force for the Randstad that becomes less attractive for other reasons. At the regional scale the trend towards suburbanization seems to be mitigated by relative attractiveness of larger municipalities for realization of suitable employment-residential arrangement for dual earner households. The increased concentration of power couples in the Randstad and the Intermediate zone can be interpreted as part of a self-reinforcing process of spatial concentration. The brain drain makes the Periphery a less attractive region for starting new business activities, and the inflow of highly 
educated workers makes the Randstad and the Intermediate zone more attractive in this respect. As a result, local labor markets in the Periphery become less dense, and those in the remainder of the country even more dense, accelerating the outflow of power couples. On the other hand, it must be observed that the results presented above also suggest that there exist important forces that make the Randstad less attractive as a region of residence. If these forces become stronger, the chain of cumulative causality may be broken. The probable result will be that the Intermediate zone will gain, whereas the relative position of the Periphery may also improve. 


\section{References}

Bernasco, W. (1994) Coupled Careers: The Effect of Spouse's Resources on Success at Work. PhD thesis, Utrecht University.

Costa, D.L. \& Kahn, M.E (2000). Power Couples: Changes in the Locational Choice of the College Educated, 1940-1990. Quarterly Journal of Economics, 115, 1287-1315.

Frank, R.H. (1978) Family Location Constraints and the Geographic Distribution of Female Professionals. Journal of Political Economy, 86, 117-130.

Freedman, O. \& Kern, C.R. (1997) A Model of Workplace and Residence Choice in TwoWorker Households. Regional Science and Urban Economics. 27, 241-260.

Glaeser, E.L. (1999) Learning in Cities. Journal of Urban Economics, 46, 254-277.

Glaeser, E.L. \& Maré, D.C. (2001) Cities and Skills. Journal of Labor Economics, 19, 316-342.

Glaeser, E.L., Kahn, M.E. \& Rappaport, J. (2000) Why do the poor live in cities? Discussion paper 1891, Harvard Institute of Economic Research.

Helsley, R.W. \& Strange, W.C. (1990) Matching and Agglomeration Economies in a System of Cities Regional Science and Urban Economics, 20, 189-212.

Iranzo, S. (2003) Wages and Diversity of Skills in Cities. Working paper, dept. of economics, University of California, Davis.

Kim, S. (1989) Labor Specialization and the Extent of the Market. Journal of Political Economy, 97, 692-705.

Peri, G. (2002) Young Workers, Learning and Agglomerations. Journal of Urban Economics, 52, 582-607.

Petrongolo, B. \& Pissarides, C. (2001) Looking into the Black Box: A Survey of the Matching Function. Journal of Economic Literature, 39, 390-431.

Petrongolo, B. \& Pissarides, C. (2002) Scale Effects in Markets with Search. Working paper, Centre for Economic Performance, London School of Economics and CEPR.

Rouwendal, J. \& Rietveld. P. (1994) Changes in the Commuting Distances of Dutch Households. Urban Studies, 31, 1545-1557.

Teulings, C.N. \& Gautier P. (2000) The Right Man for the Job. Discussion paper 038/3, Tinbergen Institute.

Teulings, C.N. \& Gautier, P. (2002) Search and the City. Discussion paper 061/3, Tinbergen Institute.

Wheaton, W. (1977) Income and Urban Residence: An Analysis of Consumer demand for Location. American Economic Review, 67, 620-631. 
Figure 1: The Netherlands and the division in three zones

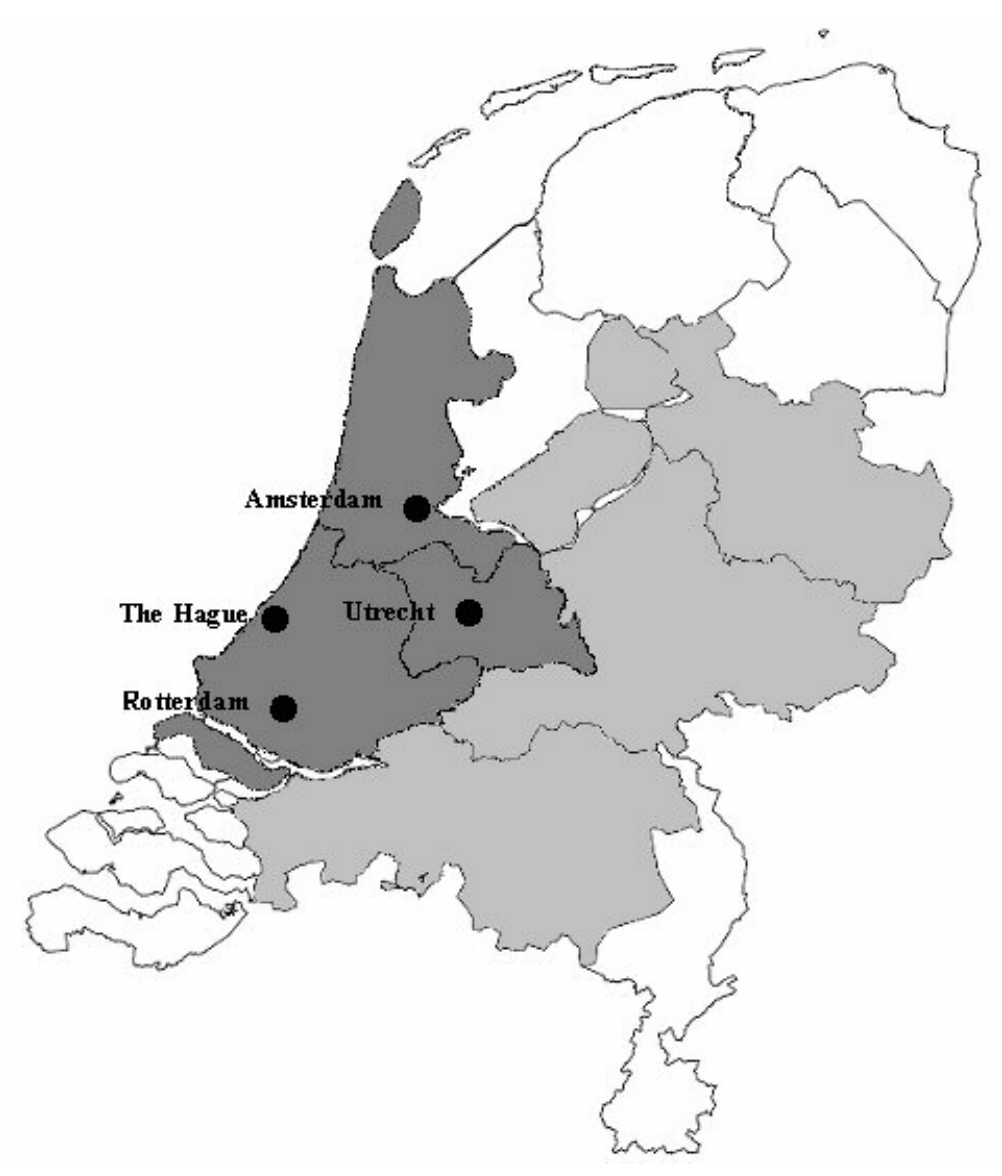


Table 1. Spatial distribution and labor force participation of couples

\begin{tabular}{lcccc}
\hline & 1981 & 1989 & 1993 & 1998 \\
\hline $\begin{array}{l}\text { Power couples } \\
\text { Randstad }\end{array}$ & 50.3 & 49.0 & 52.0 & 55.0 \\
Intermediate zone & 30.1 & 33.7 & 32.4 & 32.0 \\
$\begin{array}{l}\text { Periphery } \\
\text { Part power couples }\end{array}$ & 19.6 & 17.2 & 15.6 & 12.6 \\
Randstad & 44.2 & 41.8 & 44.8 & 47.5 \\
Intermediate zone & 33.5 & 36.9 & 36.0 & 35.7 \\
Periphery & 22.3 & 21.4 & 19.2 & 16.8 \\
Low power couples & & & & \\
Randstad & 41.5 & 39.8 & 40.3 & 39.6 \\
Intermediate zone & 37.5 & 38.5 & 38.3 & 39.6 \\
Periphery & 21.0 & 21.8 & 21.4 & 20.8 \\
\hline
\end{tabular}


Table 2: Urban amenities for various types of couples

\begin{tabular}{|c|c|c|c|}
\hline Power couples & $\begin{array}{l}\text { Coincidental power } \\
\text { couples }\end{array}$ & Low power couples & $\begin{array}{l}\text { Coincidental low } \\
\text { power couples }\end{array}$ \\
\hline $\begin{array}{l}\text { - } \text { solution co- } \\
\text { location problem } \\
\text { for higher } \\
\text { educated; } \\
\text { - urban amenities of } \\
\text { general interest. }\end{array}$ & $\begin{array}{l}\text { urban amenities of } \\
\text { general interest; } \\
\text { urban amenities of } \\
\text { specific interest } \\
\text { for higher } \\
\text { educated singles. }\end{array}$ & $\begin{array}{l}\text { - } \text { solution co- } \\
\text { location problem } \\
\text { for lower } \\
\text { educated; } \\
\text { - urban amenities of } \\
\text { general interest. }\end{array}$ & $\begin{array}{l}\text { - urban amenities of } \\
\text { general interest; } \\
\text { - urban amenities of } \\
\text { specific interest } \\
\text { for lower educated } \\
\text { singles. }\end{array}$ \\
\hline
\end{tabular}


Table 3: Computation of colocation effects

Randstad Intermediate zone Periphery

All couples

Differences 1998-1981

$\triangle$ power couples

$\begin{array}{ll}0.074 & 0.009\end{array}$

$-0.083$

$\Delta$ low power couples

$-0.069$

0.052

0.017

$\Delta$ coinc. power couples

$-0.036$

$-0.036$

0.071

$\Delta$ coinc. low power couples

$-0.099$

0.106

$-0.008$

Double differences 1998-1981

$\Delta$ power couples $-\Delta$ coinc. power couples

$0.109 \quad 0.044$

$-0.154$

$\Delta$ low power couples $-\Delta$ coinc. low power cpls.

0.030

$-0.054$

0.024

Triple differences 1998-1981

[ $\Delta$ power cpls. $-\Delta$ coinc. power cpls. $]-$

0.079

0.099

$-0.178$

[ $\Delta$ low power cpls. $-\Delta$ coinc. low power cpls.]

\section{Couples with both partners employed}

Differences 1998-1981

$\Delta$ power couples

0.287

0.142

0.033

$\Delta$ low power couples

0.131

0.216

0.106

$\Delta$ coinc. power couples

$-0.092$

0.033

0.060

$\Delta$ coinc. low power couples

$-0.106$

0.091

0.015

Double differences 1998-1981

$\Delta$ power couples $-\Delta$ coinc. power couples $\quad 0.380$

0.110

$-0.026$

$\Delta$ low power couples $-\Delta$ coinc. low power cpls.

0.237

0.125

0.091

Triple differences 1998-1981

[ $\Delta$ power cpls. $-\Delta$ coinc. power cpls.] -

$0.142 \quad-0.015$

$-0.118$ 
Table 4: Hourly wage rates

\begin{tabular}{|c|c|c|c|c|}
\hline Variable & (1) & (2) & (3) & (4) \\
\hline Constant & 3.39 & 3.49 & 3.46 & 3.47 \\
\hline Age & 0.0423 & 0.0400 & 0.0401 & 0.0401 \\
\hline Age squared & -0.000434 & -0.000412 & -0.000415 & -0.000415 \\
\hline Female & -0.277 & -0.219 & -0.220 & -0.218 \\
\hline Only basic education & -0.0965 & -0.0995 & -0.0973 & -0.0973 \\
\hline Higher voc. training & 0.203 & 0.209 & 0.207 & 0.208 \\
\hline University & 0.308 & 0.329 & 0.376 & 0.375 \\
\hline Fem*higher voc. tr. & 0.0253 & -0.0180 & -0.0185 & -0.0179 \\
\hline Fem* univ. & 0.0911 & 0.0219 & 0.0201 & 0.0167 \\
\hline Single & & -0.207 & -0.211 & -0.210 \\
\hline Dual earners & & -0.0474 & -0.0495 & -0.0560 \\
\hline Power couple & & -0.00570 & -0.00609 & 0.00731 \\
\hline Fem*single & & 0.135 & 0.133 & 0.133 \\
\hline Fem*dual earners & & -0.0560 & -0.0557 & -0.0568 \\
\hline Fem*power couple & & 0.0723 & 0.0719 & 0.0411 \\
\hline Randstad & & & 0.0604 & 0.0499 \\
\hline Intermediate zone & & & 0.0164 & 0.0152 \\
\hline Randstad*univ. & & & -0.0662 & -0.0626 \\
\hline Randstad*higher voc. training & & & -0.00852 & -0.0103 \\
\hline Int. zone* univ. & & & -0.0569 & -0.0542 \\
\hline Int. zone * higher voc. training & & & 0.0155 & 0.0165 \\
\hline Randstad*dual earners & & & & 0.0153 \\
\hline Int. zone* dual earners & & & & -0.0213 \\
\hline Randstad*power couple & & & & -0.0213 \\
\hline Int. zone* power couple & & & & -0.0119 \\
\hline Fem*power couples*Randstad & & & & 0.0509 \\
\hline Fem*power couple*Int. zone & & & & 0.0208 \\
\hline$R^{2}$ & 0.23 & 0.24 & 0.25 & 0.25 \\
\hline
\end{tabular}

Dependent variable: $\ln$ of hourly wage rate. Bold figures indicate significant coefficients. All equations are estimated on 47403 observations using OLS. 
Table 5: Commuting distances

\begin{tabular}{|c|c|c|c|c|}
\hline Variable & (1) & (2) & (3) & (4) \\
\hline Constant & 0.182 & 0.258 & 0.213 & 0.424 \\
\hline Age & -0.00783 & -0.00753 & -0.00756 & -0.00793 \\
\hline Female & -0.200 & -0.270 & -0.268 & -0.241 \\
\hline Only basic education & -0.129 & -0.130 & -0.127 & -0.136 \\
\hline Higher vocational training & 0.137 & 0.134 & 0.0851 & 0.0873 \\
\hline University & 0.0992 & 0.106 & -0.105 & -0.0794 \\
\hline Fem*higher voc. tr. & 0.0472 & -0.00137 & -0.00803 & -0.00489 \\
\hline Fem*university & 0.309 & 0.238 & 0.234 & 0.245 \\
\hline $\operatorname{Ln}($ wage rate) & 0.383 & 0.371 & 0.362 & 0.350 \\
\hline Working hours / 40 & 0.654 & 0.641 & 0.633 & 0.626 \\
\hline Single & & -0.173 & -0.189 & -0.152 \\
\hline Dual earners & & 0.0107 & 0.00529 & 0.0897 \\
\hline Power couple & & 0.0179 & 0.0140 & 0.0231 \\
\hline Fem*single & & 0.118 & 0.111 & 0.0874 \\
\hline Fem* dual earners & & 0.0680 & 0.0608 & 0.0276 \\
\hline Fem* power couple & & 0.106 & 0.169 & 0.171 \\
\hline \# persons $0-5$ & & -0.00153 & -0.00348 & -0.00802 \\
\hline \# persons 6-11 & & -0.0158 & -0.0143 & -0.0195 \\
\hline \# persons $12-17$ & & -0.0341 & -0.0328 & -0.0380 \\
\hline Fem* \# persons $0-5$ & & -0.0472 & -0.0488 & -0.0494 \\
\hline Fem* \# persons 6-11 & & -0.0855 & -0.0886 & -0.0888 \\
\hline Fem* \# persons $12-17$ & & -0.0192 & -0.0208 & -0.0211 \\
\hline Randstad & & & 0.161 & 0.220 \\
\hline Intermediate zone & & & 0.0947 & 0.121 \\
\hline Randstad* university & & & 0.249 & 0.255 \\
\hline Int. zone* university & & & 0.216 & 0.210 \\
\hline Randstad* higher voc. training & & & 0.0688 & 0.0656 \\
\hline Int. zone* higher voc. training & & & 0.0604 & 0.0637 \\
\hline Fem* Randstad*power couple & & & -0.129 & -0.126 \\
\hline Fem* Int. zone*power couple & & & 0.00422 & 0.000279 \\
\hline \multicolumn{5}{|c|}{ Size of municipality $(0-5,000=$ reference $)$} \\
\hline $5,000-10,000$ inhabitants & & & & -0.000710 \\
\hline $10,000-20,000$ & & & & -0.0809 \\
\hline $20,000-50,000$ & & & & -0.209 \\
\hline $50,000-100,000$ & & & & -0.219 \\
\hline $100,000-150,000$ & & & & -0.250 \\
\hline $150,000-250,000$ & & & & -0.328 \\
\hline At least 250,000 & & & & -0.349 \\
\hline$R^{2}$ & 0.089 & 0.092 & 0.096 & 0.101 \\
\hline
\end{tabular}

Bold figures indicate significant coefficients. 
Table 6: Distribution of households over Randstad, Intermediate zone and Periphery

\begin{tabular}{lcc}
\hline Variable & Randstad & Intermediate zone \\
\hline Constant & $\mathbf{0 . 1 2 4}$ & $\mathbf{0 . 2 8 1}$ \\
Income (x1000) & $\mathbf{0 . 0 0 0 7 7 7}$ & $\mathbf{0 . 0 0 0 4 3 6}$ \\
Age head household & $\mathbf{- 0 . 0 0 1 8 9}$ & $\mathbf{- 0 . 0 0 3 0 0}$ \\
Dual earners & -0.0701 & $\mathbf{- 0 . 0 5 4 7}$ \\
Power couple & $\mathbf{0 . 1 9 8}$ & 0.0755 \\
Single & $\mathbf{0 . 3 5 7}$ & -0.0320 \\
Power single & $\mathbf{0 . 5 4 7}$ & $\mathbf{0 . 2 9 6}$ \\
Loglikelihood & & -58224 \\
\hline
\end{tabular}

Bold figures indicate significant coefficients. 
Table 7: Distribution of households over municipalities of different size

\begin{tabular}{llcccccc}
\hline Variable & $5,000-$ & $10,000-$ & $20,000-$ & $50,000-$ & $100,000-$ & $150,000-$ & At least \\
& 10,000 & 20,000 & 50,000 & 100,000 & 150,000 & 250,000 & 250,000 \\
\hline Constant & $\mathbf{1 . 8 7}$ & $\mathbf{2 . 8 5}$ & $\mathbf{3 . 0 1}$ & $\mathbf{2 . 7 7}$ & $\mathbf{2 . 2 8}$ & $\mathbf{2 . 1 0}$ & $\mathbf{2 . 3 1}$ \\
$\begin{array}{l}\text { Income } \\
\text { (x 1000) }\end{array}$ & -0.00464 & -0.000145 & -0.00117 & $\mathbf{- 0 . 0 0 3 2 8}$ & $\mathbf{- 0 . 0 0 5 3 1}$ & $\mathbf{- 0 . 0 1 1 5}$ & $\mathbf{- 0 . 0 9 4 2}$ \\
$\begin{array}{l}\text { Age hh. } \\
\text { Dual }\end{array}$ & -0.00437 & $\mathbf{- 0 . 0 0 5 9 6}$ & $\mathbf{- 0 . 0 0 8 2 8}$ & $\mathbf{- 0 . 0 1 3 5}$ & $\mathbf{- 0 . 0 1 5 9}$ & $\mathbf{- 0 . 0 2 1 3}$ & $\mathbf{- 0 . 0 1 5 6}$ \\
$\begin{array}{l}\text { earners } \\
\text { Power }\end{array}$ & 0.112 & 0.0899 & 0.144 & $\mathbf{0 . 3 3 6}$ & $\mathbf{0 . 3 7 5}$ & $\mathbf{0 . 4 6 0}$ & $\mathbf{0 . 2 5 4}$ \\
$\begin{array}{l}\text { couple } \\
\text { Single }\end{array}$ & -0.178 & 0.151 & 0.296 & $\mathbf{0 . 3 2 0}$ & $\mathbf{0 . 7 8 0}$ & $\mathbf{1 . 0 4}$ & $\mathbf{0 . 8 5 4}$ \\
$\begin{array}{l}\text { Power } \\
\text { single }\end{array}$ & -0.108 & -0.240 & 0.157 & 0.419 & $\mathbf{0 . 8 5 7}$ & $\mathbf{1 . 0 3}$ & $\mathbf{0 . 9 5 7}$ \\
\hline
\end{tabular}

The table reports estimates of a multinomial logit model. Municiplaiites of the smallest size (05,000 inhabitant) were taken as the reference class. Loglikelihood: $-100,056.26$. Bold figures indicate significant coefficients. 
Table 8: Logit model for the choice between rental and owner-occupied housing

\begin{tabular}{ll}
\hline Variable & Estimate \\
\hline Constant & $\mathbf{- 3 . 4 2}$ \\
Income & $\mathbf{0 . 0 3 7 7}$ \\
Age head household & $\mathbf{0 . 1 2 2}$ \\
Age h.h. squared & $\mathbf{- 0 . 0 0 1 1 4}$ \\
Dual earners & $\mathbf{- 0 . 2 6 3}$ \\
Power couple & $\mathbf{0 . 3 7 6}$ \\
Single & $\mathbf{- 0 . 6 8 3}$ \\
Power single & $\mathbf{0 . 3 3 0}$ \\
Randstad & $\mathbf{0 . 0 5 2 1}$ \\
Intermediate zone & $\mathbf{- 0 . 1 7 0}$ \\
Size of municipality $(0-5,000=$ reference $)$ & \\
5,000-10,000 inhabitants & $\mathbf{- 0 . 1 7 5}$ \\
10,000-20,000 & $\mathbf{- 0 . 3 2 3}$ \\
20,000-50,000 & $\mathbf{- 0 . 7 3 3}$ \\
50,000-100,000 & $\mathbf{- 1 . 0 7}$ \\
100,000-150,000 & $\mathbf{- 1 . 2 6}$ \\
150,000-250,000 & $\mathbf{- 1 . 3 7}$ \\
At least 250,000 & $\mathbf{- 2 . 1 8}$ \\
Loglikelihood & $-29,785$ \\
\hline
\end{tabular}

The dependent variable is a dummy for owner-occupied housing. 
Table 9: The value of owner-occupied houses

\begin{tabular}{lcc}
\hline Variable & $(1)$ & $(2)$ \\
\hline Constant & $\mathbf{2 . 0 9}$ & $\mathbf{2 . 5 5}$ \\
Income $(x 1000)$ & $\mathbf{0 . 4 7 9}$ & $\mathbf{0 . 0 7 4 6}$ \\
Age head household & $\mathbf{0 . 0 0 4 9 2}$ & $\mathbf{0 . 0 0 4 3 5}$ \\
Dual earner & $\mathbf{- 0 . 0 6 6 0}$ & $\mathbf{- 0 . 0 2 9 7}$ \\
Power couple & $\mathbf{0 . 2 0 3}$ & $\mathbf{0 . 1 0 2}$ \\
Single & $\mathbf{- 0 . 3 0 2}$ & $\mathbf{- 0 . 0 3 6 6}$ \\
Power single & $\mathbf{0 . 2 0 7}$ & $\mathbf{0 . 0 6 2 7}$ \\
Randstad & $\mathbf{0 . 2 1 4}$ & $\mathbf{0 . 2 0 5}$ \\
Intermediate zone & $\mathbf{0 . 2 3 4}$ & $\mathbf{0 . 2 5 3}$ \\
Size of municipality $(0-5000=$ reference $)$ & & \\
$5,000-10,000$ & $\mathbf{- 0 . 0 4 6 5}$ & -0.0170 \\
$10,000-20,000$ & $\mathbf{- 0 . 0 8 9 5}$ & -0.0370 \\
$20,000-50,000$ & $\mathbf{- 0 . 1 1 1 4}$ & 0.00996 \\
$50,000-100,000$ & $\mathbf{- 0 . 2 4 2 0}$ & $\mathbf{- 0 . 0 5 9 1}$ \\
$100,000-150,000$ & $\mathbf{- 0 . 1 9 9 2}$ & 0.0213 \\
$150,000-250,000$ & $\mathbf{- 0 . 3 4 1 3}$ & $\mathbf{- 0 . 0 8 0 8}$ \\
At least 250,000 & $\mathbf{- 0 . 5 1 9 3}$ & $\mathbf{- 0 . 0 6 9 4}$ \\
$\lambda$ & & $\mathbf{- 0 . 5 9 6}$ \\
$R^{2}$ & 0.1672 & \\
\hline Dep & & \\
\hline
\end{tabular}

Dependent variable is $\ln$ (self reported value of the house). Bold figures indicate significant coefficients. 